\title{
Ghrelin Increases GABAergic Transmission and Interacts with Ethanol Actions in the Rat Central Nucleus of the Amygdala
}

\author{
Maureen T Cruz', Melissa A Herman', Dawn M Cote², Andrey E Ryabinin² and Marisa Roberto*,' \\ 'Committee on the Neurobiology of Addictive Disorders, The Scripps Research Institute, La Jolla, CA, USA; '2Department of Behavioral \\ Neuroscience, School of Medicine, Oregon Health and Science University, Portland, OR, USA
}

\begin{abstract}
The neural circuitry that processes natural rewards converges with that engaged by addictive drugs. Because of this common neurocircuitry, drugs of abuse have been able to engage the hedonic mechanisms normally associated with the processing of natural rewards. Ghrelin is an orexigenic peptide that stimulates food intake by activating GHS-RIA receptors in the hypothalamus. However, ghrelin also activates GHS-RI A receptors on extrahypothalamic targets that mediate alcohol reward. The central nucleus of the amygdala (CeA) has a critical role in regulating ethanol consumption and the response to ethanol withdrawal. We previously demonstrated that rat CeA GABAergic transmission is enhanced by acute and chronic ethanol treatment. Here, we used quantitative RT-PCR (qRT-PCR) to detect Ghsr mRNA in the CeA and performed electrophysiological recordings to measure ghrelin effects on GABA transmission in this brain region. Furthermore, we examined whether acute or chronic ethanol treatment would alter these electrophysiological effects. Our qRT-PCR studies show the presence of Ghsr mRNA in the CeA. In naive animals, superfusion of ghrelin increased the amplitude of evoked inhibitory postsynaptic potentials (IPSPs) and the frequency of miniature inhibitory postsynaptic currents (mIPSCs). Coapplication of ethanol further increased the ghrelin-induced enhancement of IPSP amplitude, but to a lesser extent than ethanol alone. When applied alone, ethanol significantly increased IPSP amplitude, but this effect was attenuated by the application of ghrelin. In neurons from chronic ethanol-treated (CET) animals, the magnitude of ghrelin-induced increases in IPSP amplitude was not significantly different from that in naive animals, but the ethanol-induced increase in amplitude was abolished. Superfusion of the GHS-RIA antagonists D-Lys3-GHRP-6 and JMV 3002 decreased evoked IPSP and mIPSC frequency, revealing tonic ghrelin activity in the CeA. D-Lys3-GHRP-6 and JMV 3002 also blocked ghrelin-induced increases in GABAergic responses. Furthermore, D-Lys3-GHRP-6 did not affect ethanol-induced increases in IPSP amplitude. These studies implicate a potential role for the ghrelin system in regulating GABAergic transmission and a complex interaction with ethanol at CeA GABAergic synapses.

Neuropsychopharmacology (2013) 38, 364-375; doi:I0.1038/npp.2012.190; published online 12 September 2012
\end{abstract}

Keywords: electrophysiology; neuroadaptation; central nucleus of the amygdala; ghrelin; ethanol; alcohol dependence

\section{INTRODUCTION}

The extended amygdala has a critical role in the motivational effects of drugs of abuse and the reinforcing properties of ethanol (Koob et al, 1998; Koob, 2003). The central nucleus of the amygdala (CeA) is a major component of the extended amygdala and is implicated in the behavioral and physiological responses associated with alcohol consumption (Nie et al, 1994; Funk et al, 2006) and anxiety (LeDoux et al, 1988; Walker and Davis, 1997). Behavioral studies have demonstrated that GABAergic transmission in the CeA is involved in the regulation of

* Correspondence: Dr M Roberto, Committee on Neurobiology of Addictive Disorders, The Scripps Research Institute, SP30- I I 60, 10550 N. Torrey Pines Road, La Jolla, CA 92037, USA, Tel: + I 8587847262 , Fax: + I 858784 7405, E-mail: mroberto@scripps.edu Received 4 April 2012; revised 3 August 2012; accepted 15 August 2012 alcohol intake (Hyytia and Koob, 1995; McBride et al, 1998). Microinjection of $\mathrm{GABA}_{\mathrm{A}}$ receptor antagonists into the CeA blocks the reinforcing effect of alcohol (Hyytia and Koob, 1995), and injection of $\mathrm{GABA}_{\mathrm{A}}$ receptor agonists and benzodiazepines into the CeA decreases anxiety (Roberts et al, 1996), supporting the involvement of the CeA GABAergic system in ethanol reinforcement. We have previously reported that ethanol augments GABAergic transmission in CeA neurons via a presynaptic mechanism that enhances GABA release (Roberto et al, 2003, 2010; Nie et al, 2004; Bajo et al, 2008).

Ghrelin is a 28 -amino acid orexigenic peptide that can induce hyperphagia (Kojima et al, 1999). This peptide is synthesized mainly in the gut, but it has been reported to be centrally produced in the brain (Cowley et al, 2003), mainly in the hypothalamus. Ghrelin-positive processes have also been reported outside of the hypothalamus, including the bed nucleus of stria terminalis, medial, central, and cortical amygdalae, the thalamic paraventricular nucleus, and the 
lateral habenula (Cowley et al, 2003). Some laboratories have also argued against the presence of ghrelin in the CNS (Furness et al, 2011).

Ghrelin is an endogenous ligand of the growth hormone secretagogue receptor (GHS-R1A), a G-protein-coupled receptor that binds $\mathrm{G} \alpha_{\mathrm{q}}$ and results in increased intracellular calcium when activated. GHS-R1As are expressed widely in the brain and peripheral tissues (eg, stomach, intestine, pancreas, thymus, gonads, thyroid, and heart). In the brain, relative expression of Ghsr mRNA encoding GHS$\mathrm{R} 1 \mathrm{~A}$ differs across species (Landgren et al, 2011a). The most consistent brain sites of Ghsr mRNA expression across mice and rats include the arcuate nucleus, the suprachiasmatic nucleus, centrally projecting Edinger-Westphal nucleus (EWcp), area postrema, substantia nigra, and the ventral tegmental area (VTA) (Guan et al, 1997; Landgren et al, 2011a). Although initial characterizations did not report GHS-R1As in the amygdala, a recent study using quantitative reverse transcription-PCR (qRT-PCR) amplified Ghsr mRNA in dissections of amygdala at levels comparable to those in the VTA and higher than those in the nucleus accumbens or cortex of alcohol-experienced rats (Landgren et al, 2011b).

Increasing evidence points to the ghrelin system as having an important role in ethanol intake and reward. Genetic studies have shown an association between the singlenucleotide polymorphism (SNP) rs2232165 of the GHSR gene and heavy alcohol use (Landgren et al, 2008). Elevated plasma ghrelin levels have been reported in alcoholic patients (Kim et al, 2005; Kraus et al, 2005; Wurst et al, 2007), and among alcoholics, there is a strong positive correlation between ghrelin levels and craving (Addolorato et al, 2006; Leggio et al, 2012). However, other investigators found reduced ghrelin levels in alcoholics (Addolorato et al, 2006; Badaoui et al, 2008). These conflicting results have prompted studies investigating which neural substrates are involved in central ghrelin signaling and behavioral responses to ethanol intake. In mice, injection of ghrelin targeting the VTA and laterodorsal tegmental area (LDTg) produced an increase in alcohol consumption on the twobottle choice test (Jerlhag et al, 2009). This increase in alcohol intake was reversed by administration of GHS-R1A antagonists and was absent in GHSR knockout mice (Jerlhag et al, 2009). Furthermore, injection of GHS-R1A antagonists targeting the VTA and LDTg attenuated both ethanolinduced locomotor stimulation and ethanol-induced dopamine release, measures of ethanol reward (Jerlhag et al, 2009). Recent studies suggest that the EWcp (also known as the perioculomotor urocortin-containing neurons) may be involved in the regulation of ethanol intake. Intraperitoneal injection of a GHS-R1A antagonist produced a reduction in alcohol preference and intake in mice, and this reduction in consumption was accompanied by a decrease of c-Fos immunopositive cells in the EWcp, but not the VTA or the arcuate nucleus (Kaur and Ryabinin, 2010).

The CeA is innervated by ghrelin-containing axon terminals (Cowley et al, 2003) and there is an increase in GHS-R1A gene expression in the amygdala of high-ethanolpreferring AA rats $v s$ ethanol-avoiding ANA rats following alcohol self-administration (Landgren et al, 2011b). However, to our knowledge, there are no data available on the electrophysiological effects of ghrelin in CeA neurons. Here, we hypothesized that ghrelin signaling in the CeA modulates the effects of ethanol on GABAergic transmission and, consequently, may play a role in alcohol reinforcement and excessive drinking. We found that ghrelin acts through the GHS-R1A to increase GABA release. Tonic ghrelin signaling is present in CeA neurons, and the basal ghrelin signaling pathway in the CeA appears to interact with pathways activated by both acute and chronic ethanol exposure.

\section{MATERIALS AND METHODS}

\section{Slice Preparation}

As previously described (Roberto et al, 2003, 2004), we prepared CeA slices from male Sprague-Dawley rats (150-300 g; 7-9 weeks old; $n=103$ ) that were anesthetized with halothane in isoflurane (3\%) and decapitated. We cut 400 $\mu \mathrm{m}$ transverse slices on a Vibratome Series 3000 (Technical Products International, St Louis, MO), incubated them in an interface configuration for about $30 \mathrm{~min}$, and then completely submerged and continuously superfused them (flow rate of $2-4 \mathrm{ml} / \mathrm{min})$ with warm $\left(31^{\circ} \mathrm{C}\right)$, gassed ACSF of the following composition in $\mathrm{mM}: \mathrm{NaCl}, 130 ; \mathrm{KCl}, 3.5 ; \mathrm{NaH}_{2} \mathrm{PO}_{4}$, 1.25; $\mathrm{MgSO}_{4} \cdot 7 \mathrm{H} 2 \mathrm{O}, 1.5 ; \mathrm{CaCl}_{2}, 2.0 ; \mathrm{NaHCO}_{3}, 24$; glucose, 10. Drugs were added to the ACSF from stock solutions to obtain known concentrations in the superfusate.

\section{Chronic Ethanol Treatment}

We used the standard ethanol inhalation method of The Scripps Research Institute Alcohol Research Center to induce ethanol dependence (Rogers et al, 1979; Roberto et al, 2010). Briefly, male Sprague-Dawley rats were housed 2-4 per cage with a $0600 \mathrm{~h}$ to $1800 \mathrm{~h}$ light cycle and with free access to food and water. Rats were placed into either ethanol vapor chambers $(n=20)$ or air-only chambers (naive controls; $n=13$ ). Chronic ethanol-treated (CET) rats were intermittently exposed ( $14 \mathrm{~h}$ on, $10 \mathrm{~h}$ off) to ethanol vapors for 3 to 4 weeks. On experiment days, CET rats were maintained in the ethanol vapor chamber until preparation of the CeA slices (under ethanol-free conditions). We recorded from slices of CET rats $2-8 \mathrm{~h}$ after cutting the slices, as previously described (Roberto et al, 2004). Naive/control rats were exposed to air $24 \mathrm{~h} /$ day.

\section{Blood Alcohol Level (BAL)}

Twice per week, we determined BALs of the CET animals from tail-blood samples. The target range for BALs in dependent rats during vapor exposure was $150-200 \mathrm{mg} \%$. Control animals were also routinely sampled to control for possible effects of handling.

\section{Intracellular Recording}

We recorded from neurons in the medial subdivision of the CeA with sharp micropipettes filled with $3 \mathrm{M} \mathrm{KCl}$ (Roberto et al, 2004). We held most neurons near their resting membrane potentials (RMPs). Data were acquired with an Axoclamp-2A preamplifier (Axon Instruments, Foster City, CA) and stored for later analysis using pClamp software (Axon Instruments). We evoked pharmacologically isolated 
$\mathrm{GABA}_{\mathrm{A}}$ receptor-mediated inhibitory postsynaptic potentials (IPSPs) by stimulating locally within the CeA through a bipolar stimulating electrode while superfusing the slices with the glutamate receptor blockers 6,7-dinitroquinoxaline-2,3-dione (DNQX; $20 \mu \mathrm{M}$ ) and DL-2-amino-5-phosphonovalerate (APV; $30 \mu \mathrm{M})$, and the $\mathrm{GABA}_{\mathrm{B}}$ receptor antagonist CGP 55845A $(1 \mu \mathrm{M})$. At the end of recording, we superfused $30 \mu \mathrm{M}$ bicuculline (or $50 \mu \mathrm{M}$ picrotoxin) to confirm the $\mathrm{GABA}_{A}$ ergic nature of the IPSPs; these antagonists completely blocked the IPSPs. To determine the synaptic response parameters for each cell, we performed an input/ output (I/O) protocol (Roberto et al, 2003, 2010) consisting of a range of five current stimulations $(50-250 \mu \mathrm{A}$; $0.125 \mathrm{~Hz}$ ), starting at the threshold current required to elicit an IPSP up to the strength required to elicit the maximum amplitude. We normalized the three middle (omitting threshold and maximal) stimulus intensities of five equal steps as $1-3$; these stimulus strengths and the half-maximal stimulus strength were maintained throughout the duration of the experiment. For some histograms (Figures 1c, 3a, 3d, and 5b) and in the time course studies (Figures 3f, 4e, and $4 \mathrm{f}$ ), we applied four consecutive stimuli (at $30 \mathrm{~s}$ intervals) at the half-maximal amplitude determined from the I/O relationship. We examined pairedpulse facilitation (PPF) in each neuron using paired stimuli at 50 and $100 \mathrm{~ms}$ interstimulus intervals (Zucker, 1989; Bonci and Williams, 1997; Roberto et al, 2004). The stimulus strength was adjusted such that the amplitude of the first IPSP was half-maximal. We calculated the PPF ratio as the amplitude of the second IPSP over the amplitude of the first.

All measures were taken before drug superfusion (control), during drug superfusion (10-30 min, depending on the drug), and following washout $(20-30 \mathrm{~min})$, and are expressed as mean \pm SEM. We used $t$-test analyses to evaluate differences in individual means between two groups (eg, when the effect of each dose of ghrelin or the GHS-R1A antagonists, D-Lys3-GHRP-6 and JMV 3002, were compared with the respective baseline values). We also used within-subject one-way RM ANOVA to compare IPSPs in the same group of cells (naive or dependent rats) after application of different drugs. When appropriate, the Student Newman-Keuls post hoc test was used to assess significance between treatments with $p<0.05$ considered significant. To assess differences resulting from ethanol exposure (naive $x$ dependent) and drug interaction between groups, we used a two-way RM ANOVA.

\section{Whole-Cell Patch-Clamp Recording of Miniature IPSCs}

We recorded from a subset of CeA neurons using the wholecell patch-clamp method in the presence of $20 \mu \mathrm{M}$ DNQX, $30 \mu \mathrm{M} \mathrm{APV}, 1 \mu \mathrm{M}$ CGP 55845A, and $1 \mu \mathrm{M}$ tetrodotoxin (TTX) to isolate action potential-independent, GABAergic miniature inhibitory postsynaptic currents (mIPSCs). Patch pipettes (3-6 M 2 ) were pulled from borosilicate glass (Warner Instruments) and filled with an internal solution containing (in $\mathrm{mM}$ ): $145 \mathrm{KCl}, 10 \mathrm{HEPES}, 2 \mathrm{MgCl}_{2}, 0.5$ EGTA, 2 Na-ATP; 0.2 Na-GTP, pH 7.2-7.3, osmolarity 275-290 mOsm. We visualized CeA neurons in brain slices $(300 \mu \mathrm{m})$ using infrared differential interference contrast (IR-DIC) optics and CCD camera (EXi Aqua, QImaging). A $60 \times$ water immersion objective (Olympus) was used for
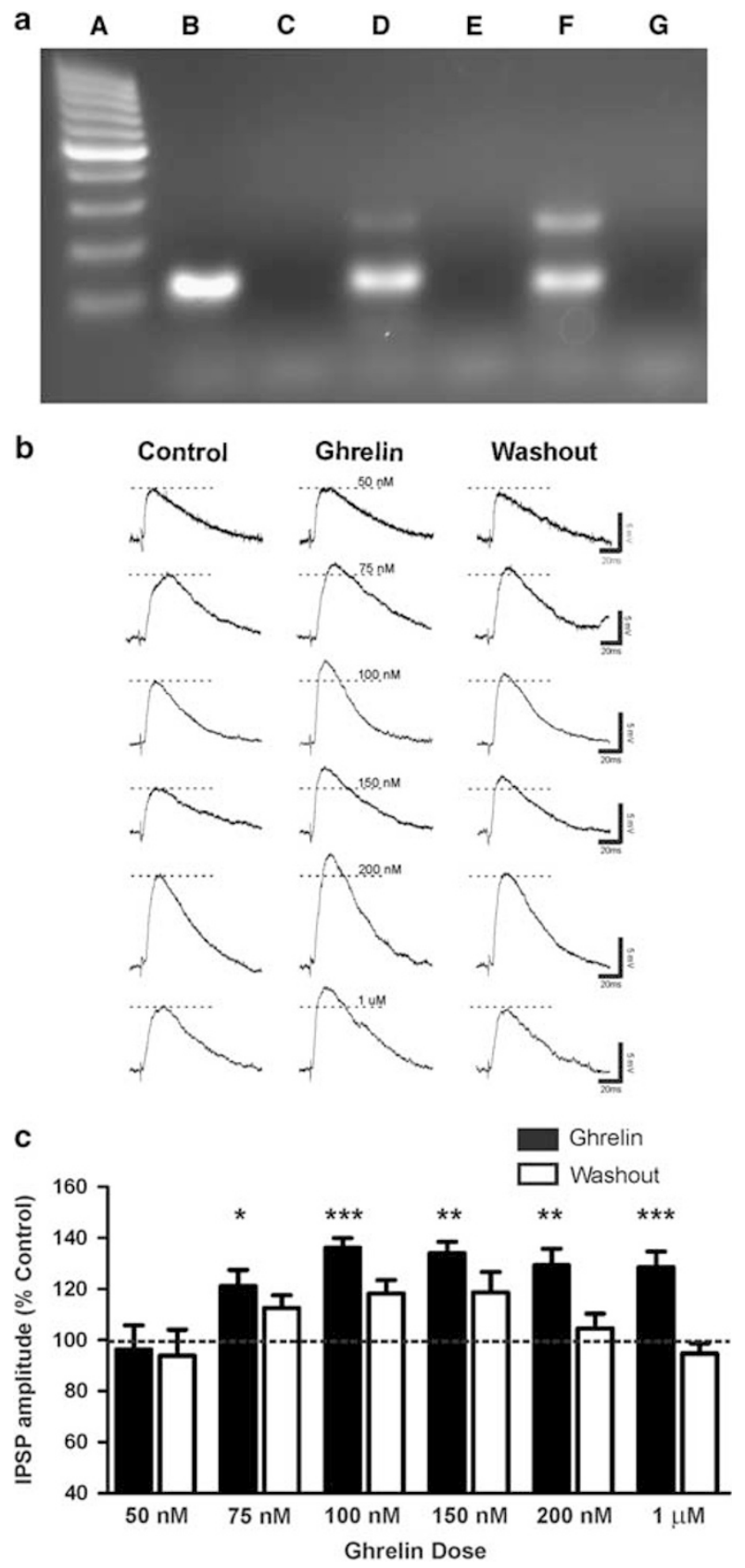

Figure I Ghsr mRNA is present in CeA neurons. (a) Gel electrophoresis of Ghsr qRT-PCR reactions: (A) size marker; (B) qRT-PCR of a hippocampal sample; (C) no reverse transcriptase control of hippocampal qRT-PCR; (D) qRT-PCR of a CeA sample; (E) no reverse transcriptase control of CeA qRT-PCR; (F) qRT-PCR of a cortex sample; (G) no reverse transcriptase control of cortex qRT-PCR. The expected amplification product size is 121 base pairs. A higher molecular weight amplified product is also visible in samples from CeA and cortex, but is of lower intensity than the specific product. (b) Representative recordings of evoked IPSPs in CeA neurons from naive rats recorded before, during ghrelin application (30 min), and washout (20 min). (c) Histograms representing percent peak increase in evoked (at half-max stimulus intensity) IPSP amplitudes during ghrelin superfusion and washout. Treatment of slices with 50,75, 100, 150 , 200 , and $1000 \mathrm{nM}$ ghrelin increased IPSP amplitude to $96.2 \pm 9.6 \%$ of control ( $p>0.05, n=5), \quad 121.2 \pm 6.2 \%$ of control (* $p<0.05, n=8)$, $\mid 36.0 \pm 4.0 \%$ (***** $p<0.00 \mid, n=24), \quad|34.| \pm 4.4 \%(* * x<0.0|, n=| 1)$, $129.2 \pm 6.6 \%(* * x<0.0 \mid, n=12)$ and $\mid 28.5 \pm 6.1 \%(* p<0.05, n=4)$, respectively. The 100-1000 nM concentrations of ghrelin produced similar facilitatory effects. 
identifying and approaching CeA neurons. Whole-cell voltageclamp recordings of mIPSCs were made with a Multiclamp 700B amplifier (Molecular Devices), low-pass filtered at $2-5 \mathrm{kHz}$, digitized (Digidata 1440A; Molecular Devices), and stored on a PC using pClamp 10 software (Axon Instruments). All cells were clamped at $-60 \mathrm{mV}$ for the duration of the recording. All data are expressed as mean \pm SEM.

In all whole-cell patch-clamp recordings, series resistance $(<10 \mathrm{M} \Omega)$ was continuously monitored with a $10 \mathrm{mV}$ hyperpolarizing pulse and experiments with $>20 \%$ change in series resistance were not included in final analysis. Frequency, amplitude, and kinetics of mIPSCs were analyzed using semiautomated threshold based mini detection software (Mini Analysis, Synaptosoft, Fort Lee, NJ) and were visually confirmed. To accurately determine the mIPSC amplitude, only mIPSCs that were $>5 \mathrm{pA}$ were accepted for analysis. We evaluated results for mIPSCs and determined statistical significance using the Kolmogorov-Smirnov, nonparametric, two-sample test, with $p<0.05$ considered significant.

\section{Drugs}

We purchased APV, DNQX, CGP 55845, ghrelin, and DLys3-GHRP-6 from Tocris Bioscience (Ellisville, MO), JMV 3002 from Cayman Chemical (Ann Arbor, MI), and TTX and bicuculline from Sigma (St Louis, MO). Ethanol was purchased from Remet (La Mirada, CA).

\section{Quantitative RT-PCR}

Using a micro-knife, we isolated CeA, hippocampus, and cortex from brain slices of naive male Sprague-Dawley rats $(n=3)$ prepared as described above. The samples were stored at $-80^{\circ} \mathrm{C}$ until use. Total RNA was extracted using the Arcturus PicoPure RNA Isolation Kit (Applied Biosystems, Carlsbad, CA). First-strand cDNA was synthesized using SABiosciences $\mathrm{RT}^{2}$ First Strand Kit (Qiagen, Frederick, MD). Quantitative RT-PCR was performed on the Mx3000P light cycler (Stratagene, La Jolla, CA) using $\mathrm{RT}^{2}$ Primer Assays for Ghsr and 18S RNA (Qiagen). Because of relatively low animal numbers in the gene expression studies, nonparametric tests were used for statistical analyses. Comparison of mean cycle thresholds for $18 \mathrm{~S}$ RNA by the Kruskall-Wallis test found no differences between brain regions $(H=0.62, p=0.73)$. CT values for Ghsr were normalized by the equation $2^{-\Delta \mathrm{CT}}$, where $\Delta \mathrm{CT}$ is the CT for Ghsr subtracted from CT for $18 \mathrm{~S}$. The normalized Ghsr values were compared between brain regions using the Kruskall-Wallis test followed by Mann-Whitney U-tests for post hoc analyses. Specificity of the Ghsr amplification was confirmed by automatic analysis of melting curves and subsequent agarose gel electrophoresis showing bands of predicted size. Lack of amplification of genomic DNA was confirmed by running the reactions without adding reverse transcriptase.

\section{RESULTS}

\section{Ghrelin Increases Inhibitory Transmission in CeA Neurons}

Quantitative RT-PCR performed on brain slices amplified Ghsr (the mRNA encoding GHS-R1A) from CeA, hippocampus, and cortex (Figure 1a). Lack of amplification in the noreverse-transcriptase control indicated that genomic DNA was not amplified. Normalized Ghsr mRNA levels were $0.005 \pm 0.003$ for hippocampus, $0.00031 \pm 0.00012$ for CeA, and $0.00011 \pm 0.00025$ for cortex. Kruskall-Wallis analysis confirmed significant differences between these values $(H=7.2, p=0.027)$. Ghsr mRNA levels were significantly higher in the hippocampus than in CeA and significantly higher in CeA than in cortex (Mann-Whitney tests: $U=9.0$, $p=0.0495$ for both comparisons). Because of the presence of Ghsr mRNA in the CeA, we investigated the electrophysiological effects of ghrelin in this region.

We performed experiments 2-8 h after preparation of CeA slices from naive rats. Using sharp micropipettes, we recorded intracellularly from neurons in the medial subdivision of the CeA. Using a stimulating electrode, we evoked synaptic GABAergic responses near the recording site. The mean RMP of these CeA neurons was $-78.3 \pm 0.7 \mathrm{mV}$ with input resistance of $139.9 \pm 4.6 \mathrm{M} \Omega(n=104)$.

We tested six different doses (50-1000 nM) of ghrelin (Figure 1b). Overall ANOVA demonstrated that $30 \mathrm{~min}$ of ghrelin superfusion increased the mean amplitude of evoked GABAergic IPSPs in CeA neurons $(\mathrm{F}(5,58)=4.06$, $p<0.01)$. As shown in Figure 1c, 75, 100, 150, 200, and $1000 \mathrm{nM}$ ghrelin increased IPSP amplitude to $121.2 \pm 6.2 \%$ $(p<0.05, n=8), 136.0 \pm 4.0 \% \quad(p<0.01, n=24), 134.1 \pm$ $4.4 \%(p<0.01, n=11), 129.2 \pm 6.6 \%(p<0.01, n=12)$, and $128.5 \pm 6.1 \% \quad(p<0.05, n=4)$, respectively. The lowest concentration of ghrelin tested ( $50 \mathrm{nM})$ did not affect IPSP amplitude (96.2 $\pm 9.6 \%$ of control; $p>0.05, n=5)$. The higher doses tested significantly and equally increased IPSP amplitude. Although we did not find the effect of these doses to be dose-dependent, our results are consistent with previous studies that found dose-dependence at concentrations $<100 \mathrm{nM}$ and a plateau effect at concentrations $>100$ nM (Yanagida et al, 2008; Kim et al, 2009). The effect of ghrelin was partially reversible upon 20-min washout (Figure 1c). Because the higher concentrations of ghrelin produced increases in IPSP amplitude similar in magnitude to the $100 \mathrm{nM}$ dose, we chose to use the $100 \mathrm{nM}$ concentration throughout the rest of the study, unless specified otherwise.

We examined the acute effects of $100 \mathrm{nM}$ ghrelin on the basic membrane properties of neurons in the medial subnucleus of the CeA. Analysis of current-voltage (I-V) relationships shows that ghrelin had no effect on membrane potential or conductance (Figure 2a). Furthermore, ghrelin had no significant effect on spike amplitudes (data not shown). In our analyses, we classified neurons as Type A or Type B according to the electrophysiological characteristics described by Schiess et al (1999). Based on the firing pattern and lack of accommodation of action potentials, we found a predominance $(85 \%)$ of Type A neurons in our recorded neuronal population, which are medium-sized spiny projecting neurons (Schiess et al, 1999). Our cell typing analysis does not reveal any significant difference in the effect of ghrelin on membrane characteristics (Supplementary Figure 1), suggesting that ghrelin may act on all cell types, and the GHS-R1A receptor may be present in all cell types.

Overall ANOVA revealed a significant effect $(\mathrm{F}(2,41)=$ $36.52, p<0.05)$ and post hoc analysis revealed that superfusion of $100 \mathrm{nM}$ ghrelin increased evoked GABA-mediated 

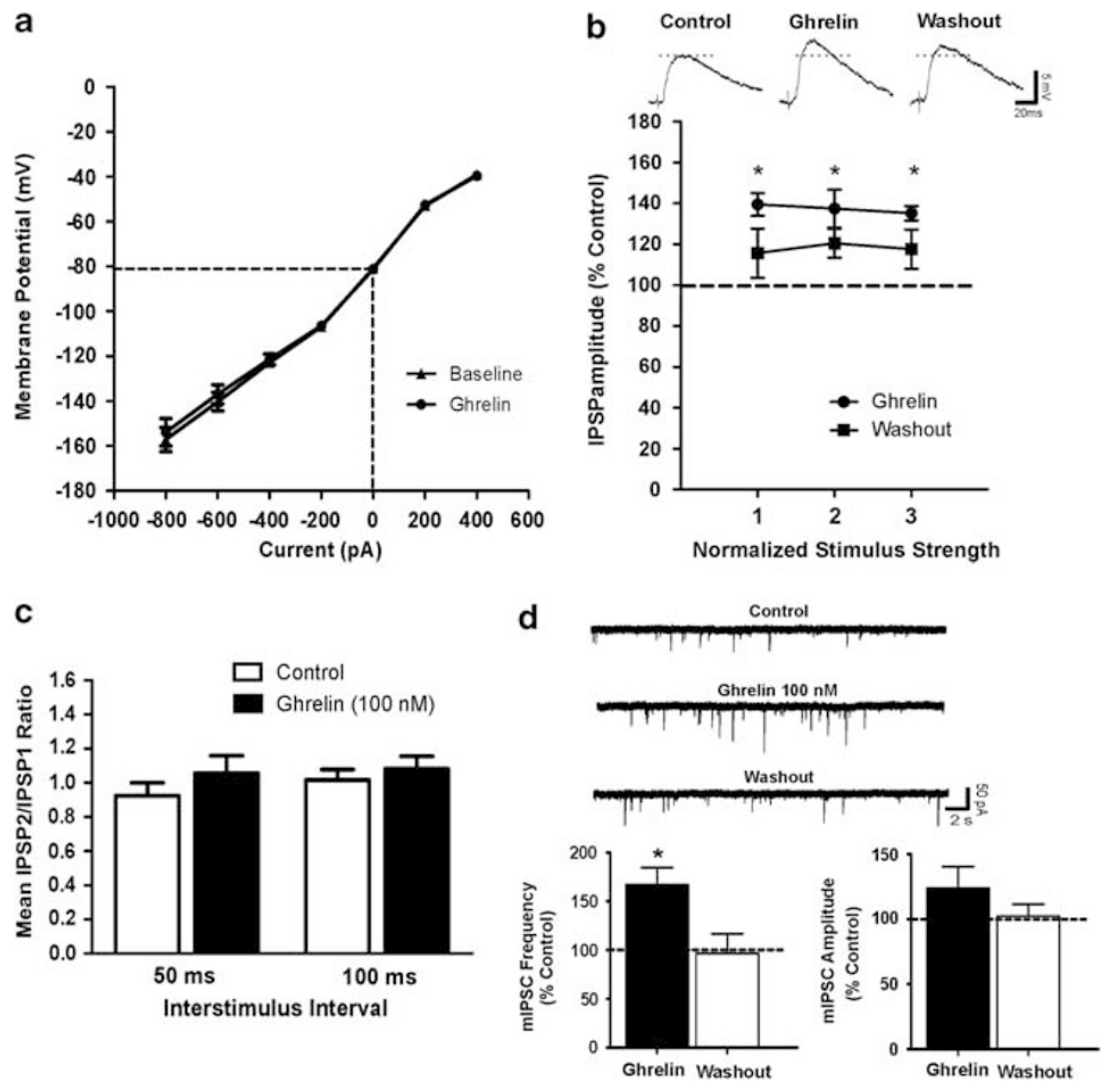

Figure 2 Ghrelin increases GABAergic transmission in CeA neurons. (a) I/V curve showing that superfusion of ghrelin (I $00 \mathrm{nM}$ ) does not change the resting membrane potential in rat CeA neurons $(n=12)$. (b, top panel) Representative IPSP recordings in a neuron from a naive rat during baseline, ghrelin $($ I $00 \mathrm{nM})$, and washout. (b, bottom panel) Ghrelin significantly $\left.{ }^{*} p<0.05, n=17\right)$ increased evoked IPSP amplitudes to I36.9 $\pm 4.3 \%$ of control (over all stimulus strengths). IPSP amplitudes recover partially upon washout. (c) Ghrelin had no significant effect on the PPF ratio of evoked IPSPs using 50 ms $(n=26)$ or $100 \mathrm{~ms}(n=27)$ interstimulus intervals. The 50 and $100 \mathrm{~ms}$ PPF ratios were $0.92 \pm 0.07(n=26)$ and $1.02 \pm 0.06$ ( $n=27)$, respectively, during control recording and $1.06 \pm 0.10$ and $1.08 \pm 0.07$, respectively, during ghrelin application. (d, top panel) Representative mIPSC recordings in CeA neurons from naive rats. (d, bottom panel) Ghrelin significantly increased the mean mIPSC frequency to $167.4 \pm 17.4 \%$ of control $(* p<0.05, n=7$ ), and also increased the mean mIPSC amplitude to $124.0 \pm 19.2 \%$ of control $(p>0.05, n=7)$.

IPSP amplitudes to $136.9 \pm 4.3 \%$ of control (averaged over all stimulus strengths; $p<0.05 ; n=17$ ) with partial recovery following 20-min washout, at which point IPSP amplitudes returned to $117.9 \pm 4.2 \%$ of control (Figure $2 \mathrm{~b}$ ). Ghrelininduced enhancement of IPSPs was measurable 5-8 min after the onset of ghrelin superfusion (see, eg, Figure 4e). In six cells, ghrelin had no effect on IPSPs.

Ghrelin could act at a pre- and/or post-synaptic site to enhance IPSP amplitude. To determine whether ghrelin alters GABA release at CeA synapses, we carried out two types of experiments. In the first set of experiments, we examined PPF at 50 and $100 \mathrm{~ms}$ interstimulus intervals, a phenomenon whereby a secondary synaptic response is influenced by a preceding primary stimulus of equal intensity (Manabe et al, 1993; Andreasen and Hablitz, 1994). Changes in the PPF ratio (second IPSP/first IPSP) are inversely related to transmitter release such that a reduction of the PPF ratio is associated with an increased probability of transmitter release. Overall, $t$-test analyses of our pairedpulse studies showed highly variable or no effects of ghrelin on PPF of IPSPs in most CeA neurons. During control recording, the 50 and $100 \mathrm{~ms}$ PPF ratios were $0.92 \pm 0.07$ $(n=26)$ and $1.02 \pm 0.06(n=27)$, respectively (Figure $2 c)$. Overall, ghrelin application did not significantly alter the 50 and $100 \mathrm{~ms}$ PPF ratios $(1.06 \pm 0.10 ; p>0.05$ and $1.08 \pm 0.07$; $p>0.05$, respectively; Figure $2 c$ ), suggesting that ghrelin could be acting both pre- and post-synaptically. However, in 10 out of the 27 cells, ghrelin decreased PPF ratios, suggesting a presynaptic effect.

To further pursue the synaptic site of ghrelin action, we studied mIPSCs in $13 \mathrm{CeA}$ neurons using whole-cell patchclamp recording in the presence of $1 \mu \mathrm{M}$ TTX. Six of the 13 cells did not respond to ghrelin. Generally, a change in mIPSC frequency indicates an altered probability of transmitter release, and a change in mIPSC amplitude reflects alterations in the sensitivity of postsynaptic $\mathrm{GABA}_{\mathrm{A}}$ receptors (De Koninck and Mody, 1994; Otis et al, 1994). Paired $t$-test analyses demonstrate that superfusion of ghrelin increased the mean frequency of mIPSCs to $167.4 \pm 17.4 \%$ of control $(p<0.05, n=7)$, and also increased the mean mIPSC amplitude to $124.0 \pm 16.4 \%$ of control $(p>0.05, n=7$; Figure 2d). Although the mean change in mIPSC amplitude did not reach statistical significance, it was significantly increased in three of the seven cells tested. Thus, acute superfusion of $100 \mathrm{nM}$ ghrelin increased mIPSC frequency in all seven cells and increased MIPSC amplitude in some cells, suggesting increased presynaptic release of GABA and postsynaptic ghrelin activity as well. Together, 
the presynaptic and postsynaptic effects may account for the lack of a significant effect on PPF due to masking/ blunting effects. After 10-min washout of the drug, mIPSC frequency was $96.8 \pm 20.1 \%$ of control $(n=4)$ and amplitude was $102.4 \pm 9.0 \%$ of control $(n=4)$.

\section{Tonic Ghrelin Activity Is Present in CeA Neurons}

To determine whether GHS-R1As regulate baseline evoked and spontaneous GABAergic transmission, and to test their involvement in ghrelin effects in the CeA, we tested D-Lys3GHRP-6, a putative selective GHS-R1A antagonist. Overall ANOVA revealed that superfusion of $50 \mu \mathrm{M}$ D-Lys3-GHRP-6 for $30 \mathrm{~min}$ decreased evoked IPSP amplitudes to $49.2 \pm 3.1 \%$ of control $(\mathrm{F}(2,26)=75.87 ; p<0.01 ; n=10$; Figure $3 \mathrm{a})$. Washout $(20 \mathrm{~min})$ only partially reversed this effect (63.9 $\pm 6.4 \%$ of control; $n=7$ ). Paired $t$-test analyses show that application of $50 \mu \mathrm{M}$ D-Lys3-GHRP-6 also decreased
mIPSC frequency $(64.98 \pm 9.2 \%$ of control; $p<0.05 ; n=5)$ and amplitude $(69.97 \pm 1.8 \%$ of control; $p<0.05 ; n=5$; Figure $3 \mathrm{c}$, left panel), and also decreased mIPSC decay (72.5 $\pm 4.0 \%$ of control; $n=5$; data not shown). The decrease in mIPSC frequency and amplitude suggest the involvement of both pre- and post-synaptic mechanisms, congruent with the ghrelin effects we observed (Figure 2c). The change in mIPSC decay suggests direct effects at the GHS-R1A or possibly nonspecific effects, perhaps due to the high dose of the antagonist (Depoortere et al, 2006; Benso et al, 2007). Thus, we also tested a lower dose $(25 \mu \mathrm{M})$ of DLys3-GHRP-6, which reduced IPSP amplitude to $65.8 \pm 3.9 \%$ of control $(\mathrm{F}(2,39)=25.61 ; p<0.01 ; n=15$; Figure $3 \mathrm{a})$ and only partially recovered after 20 -min washout $(82.2 \pm 6.5 \%$ of control; $p<0.05 ; n=10)$. Similar to ghrelin application (Figures $2 \mathrm{c}$ and $4 \mathrm{c}$ ), superfusion of D-Lys3-GHRP-6 did not alter the 50 or $100 \mathrm{~ms}$ PPF ratio at either dose (Figure 3b), suggesting both pre- and post-synaptic effects. During
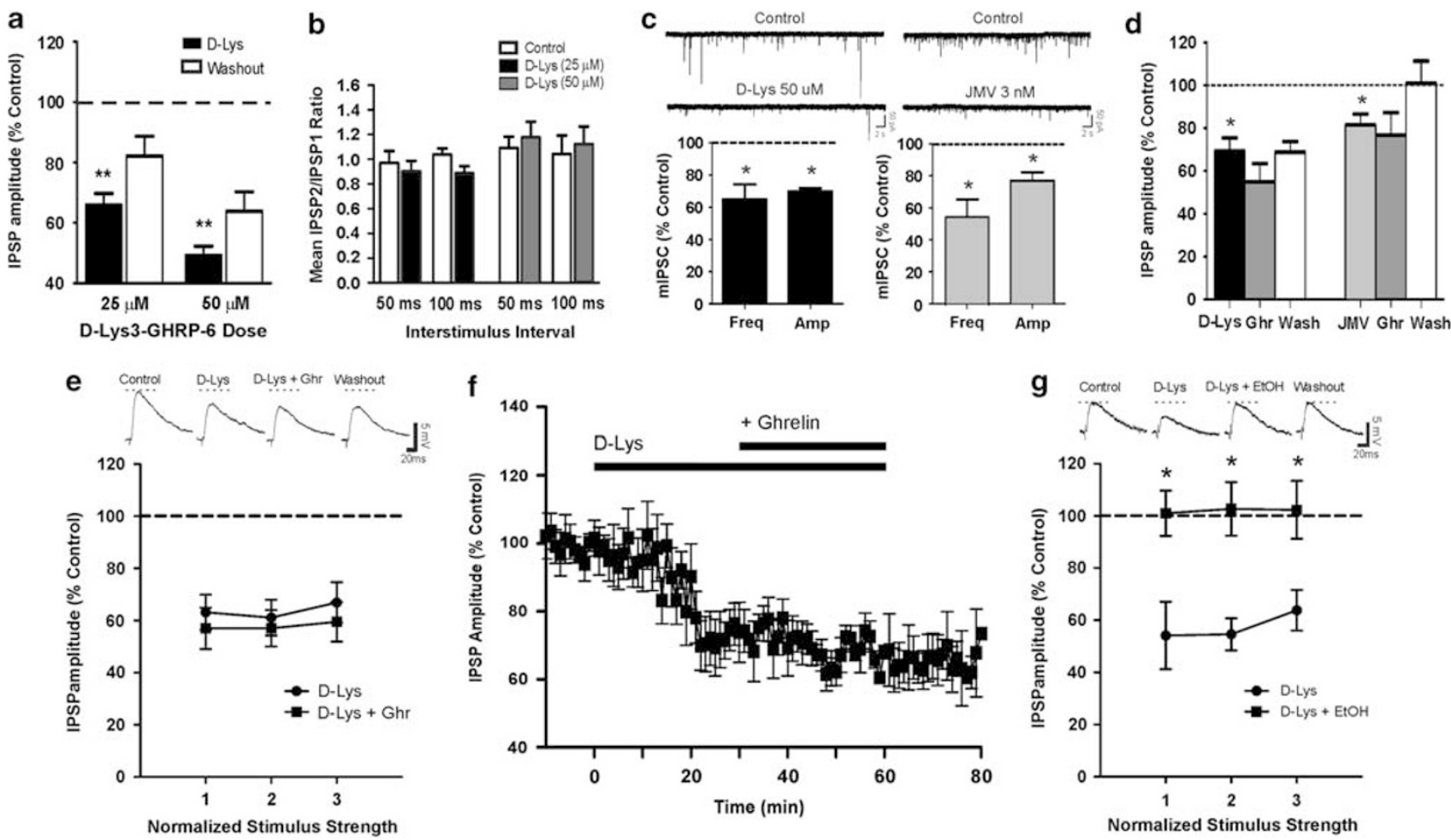

Figure 3 GHS-RIAs in the CeA are tonically active. (a) Histograms depicting change in IPSP amplitudes during D-Lys3-GHRP-6 superfusion and washout. D-Lys3-GHRP-6 $(25 \mu \mathrm{M})$ decreased amplitude to $65.8 \pm 3.9 \%$ of control $(* * p<0.01 ; n=15)$ and only partially recovered after 20 min of washout $(82.2 \pm 6.5 \%$ of control). D-Lys3-GHRP-6 $(50 \mu \mathrm{M})$ decreased evoked IPSP amplitudes to $49.2 \pm 3.1 \%$ of control $(* * * * 0<0.01 ; n=10)$. Washout partially reversed this effect (63.9 $\pm 6.4 \%$ of control). (b) There was no change in 50 and 100 ms PPF ratios with application of either $25 \mu M$ D-Lys3-GHRP-6 (control: $0.97 \pm 0.10(n=14)$ and 1.04 $\pm 0.05(n=16)$; D-Lys $(25 \mu \mathrm{M}): 0.90 \pm 0.09(n=14)$ and $0.89 \pm 0.06(n=16)]$ or $50 \mu$ M D-Lys3-GHRP-6 (control: I.09 \pm 0.09 $(n=6)$ and I.04 $\pm 0.15(n=6)$; D-Lys $(50 \mu \mathrm{M}): 1.18 \pm 0.13(n=6)$ and I.I $12 \pm 0.14(n=6))$ application. (c, top panel) Representative mIPSC recordings in rat CeA neurons. (c, bottom panel) D-Lys3-GHRP-6 $(50 \mu \mathrm{M}$ ) (left) decreased the mean mIPSC frequency $(64.98 \pm 9.2 \%$ of control; * $p<0.05 ; n=5)$ and amplitude $(69.97 \pm 1.8 \%$ of control; $* p<0.05 ; n=5)$ and JMV 3002 (right) also decreased mIPSC frequency $(55.5 \pm 10.7$ of control; $* p<0.05 ; n=7)$ and amplitude ( $76.7 \pm 5.5 \%$ of control; * $p<0.05 ; n=7$ ), indicating both pre- and postsynaptic effects of the GHS-RIA antagonists. (d) The GHS-RIA antagonists D-Lys3-GHRP-6 $(25 \mu \mathrm{M})$ and JMV 3002 (3 nM) significantly decrease IPSP amplitude and prevent ghrelin (I00 nM) from enhancing IPSP amplitude. (d, left panel) D-Lys: $69.4 \pm 6.1 \%$ of control $(n=7$; * $p<0.05)$; D-Lys with ghrelin: $55.0 \pm 8.5 \%$ of control $(n=7)$; washout: $68.9 \pm 4.9 \%$ of control $(n=6)$. (d, right panel) JMV: $81.7 \pm 5.0 \%$ of control $(n=8$; * $p<0.05)$; JMV with ghrelin: $76.9 \pm 10.3 \%$ of control $(n=5)$; washout: I0I.0 \pm I0.4\% of control $(n=5)$. (e, top panel) Representative IPSP recordings during baseline, D-Lys3-GHRP-6 $(25 \mu \mathrm{M})$, coapplication of ghrelin ( I00 nM), and washout. (e, bottom panel) D-Lys3GHRP-6 significantly decreases IPSP amplitudes to $63.7 \pm 6.9 \%$ of control $(p<0.05, n=7)$, and prevents enhancement of IPSPs induced by subsequent application of ghrelin. (f) Time course depicting changes in IPSP amplitude evoked by D-Lys3-GHRP-6, concurrent application of ghrelin, and washout ( $n=7$ ). (g, top panel) Representative IPSP recordings during baseline, D-Lys3-GHRP-6 (25 $\mathrm{MM}$ ), coapplication of ethanol (44 mM), and washout. (g, bottom panel) DLys3-GHRP-6 significantly decreases IPSP amplitudes to $57.5 \pm 7.9 \%$ of control $(p<0.05, n=4)$ and the addition of ethanol increases IPSP amplitude to $102.0 \pm 9.7 \%$ of control (* $p<0.05, n=4)$. 
control recording, the 50 and $100 \mathrm{~ms}$ PPF ratios were $0.97 \pm$ $0.10(n=14)$ and $1.04 \pm 0.05(n=16)$, respectively. Following D-Lys3-GHRP-6 $(25 \mu \mathrm{M})$ application, the PPF ratios were $0.90 \pm 0.09(n=14)$ and $0.89 \pm 0.06(n=16)$. In experiments using $50 \mu \mathrm{M}$ D-Lys3-GHRP-6, the baseline 50 and $100 \mathrm{~ms}$ PPF ratios were $1.09 \pm 0.09(n=6)$ and $1.04 \pm 0.15(n=6)$, respectively, and with the addition of D-Lys3-GHRP-6, the PPF ratios were $1.18 \pm 0.13(n=6)$ and $1.12 \pm 0.14(n=6)$. The tonic GHS-R1A activity observed in our D-Lys3-GHRP6 experiments prompted us to test another GHS-R1A antagonist (JMW 3002), to confirm these findings on both baseline evoked and spontaneous GABAergic transmission. Like D-Lys3-GHRP-6, superfusion of JMV 3002 (3 nM; Salome et al, 2009) for $30 \mathrm{~min}$ decreased evoked IPSP amplitudes (at half-max stimulus intensity) to $84.2 \pm 5.9 \%$ of control $(p<0.05, n=8$; Figure 3d). JMV 3002 had no effect on PPF ratios. During control recording, the 50 and $100 \mathrm{~ms}$ PPF ratios were $0.79 \pm 0.10(n=7)$ and $0.91 \pm 0.07$ $(n=7)$, respectively. During JMV 3002 application, the PPF ratios were $0.78 \pm 0.16(n=7)$ and $0.82 \pm 0.09(n=7)$.

To verify that ghrelin increased IPSPs in CeA by activating the GHS-R1A receptor, we treated the slices with $25 \mu \mathrm{M}$ D-Lys3-GHRP-6 and then applied $100 \mathrm{nM}$ ghrelin in the continued presence of the antagonist. Overall ANOVA revealed a significant effect of D-Lys3-GHRP-6 application $(\mathrm{F}(2,18)=18.2 ; p<0.05)$. D-Lys3-GHRP-6 decreased IPSPs to $63.7 \pm 6.9 \%$ of control (averaged over all stimulus strengths; $p<0.05 ; n=7$; Figure $3 \mathrm{e}$ ), and subsequent addition of ghrelin failed to increase IPSP amplitude; it persisted at $57.8 \pm 6.2 \%$ of control ( $n=7$; Figure $3 \mathrm{~d}$ and e). The effect of the antagonist was measurable $12 \mathrm{~min}$ after the onset of D-Lys3-GHRP-6 superfusion and reached a maximum effect after $20 \mathrm{~min}$ of superfusion (Figure $3 \mathrm{f}$ ). Following 20-min washout, IPSP amplitudes remained below baseline levels. In five neurons, we tested $100 \mathrm{nM}$ ghrelin in the presence of JMV 3002. Ghrelin did not significantly change IPSP amplitude $(76.9 \pm 10.3 \%$ of control; $n=5$; Figure $3 \mathrm{~d})$. The IPSP amplitudes returned to control (100.9 $\pm 10.4 \%, n=5)$ levels after $20 \mathrm{~min}$ of washout of the two drugs. Like D-Lys-GHRP-6, JMV 3002 blocked the ghrelin-induced facilitation of evoked IPSPs. Paired $t$-test analyses show that application of $3 \mathrm{nM} \mathrm{JMV} 3002$ also decreased mIPSC frequency $(55.5 \pm 10.7 \%$ of control; $p<0.05 ; n=7)$ and amplitude $(76.7 \pm 5.5 \%$ of control; $p<0.05 ; n=7$; Figure $3 c$, right panel), and also decreased mIPSC decay $(78.0 \pm 5.5 \%$ of control; $n=7)$. In one cell, JMV 3002 did not alter mIPSCs. Taken together, these results indicate that ghrelin exerts its effect through GHS$\mathrm{R} 1 \mathrm{As}$ and these receptors may tonically regulate CeA GABAergic activity at both pre- and post-synaptic sites.

In another set of experiments, we tested whether blockade of GHS-R1As with $25 \mu \mathrm{M}$ D-Lys3-GHRP-6 would affect ethanol-induced increases in GABAergic response. Overall ANOVA showed a significant effect of drug application $(\mathrm{F}(2,9)=12.18 ; p<0.05)$. D-Lys3-GHRP-6 decreased IPSPs to $57.5 \pm 7.9 \%$ of control (averaged over all stimulus strengths; $p<0.05 ; n=4$; Figure $3 \mathrm{~g}$ ), and the addition of ethanol increased IPSP amplitudes to $102.0 \pm 9.7 \%$ of control $(n=4$; Figure 3g). Thus, application of D-Lys3GHRP-6 did not alter ethanol-induced augmentation of IPSPs, ruling out mediation of the ethanol effects by the GHS-R1A.

\section{Acute Ethanol Interacts with Ghrelin Effects}

We have previously shown that ethanol increases GABAergic transmission in the CeA. Given the recent evidence that central ghrelin signaling influences alcohol intake (Jerlhag et al, 2009; Kaur and Ryabinin, 2010), we sought to determine whether activation of CeA GHS-R1As by ghrelin would alter the effects of ethanol on GABAergic transmission. To test the influence of GHS-R1A activation on ethanol-induced augmentation of IPSPs, we first superfused a maximal concentration of ghrelin (100-200 nM) onto CeA slices and then added $44 \mathrm{mM}$ ethanol (a dose producing maximal effects; Roberto et al, 2003; Bajo et al, 2008) in the continued presence of ghrelin. We pooled the data from different doses of ghrelin because our dose-response experiments demonstrated that there was no change in the magnitude of effect at these different concentrations (Figure 1c). Overall ANOVA demonstrated that superfusion of ghrelin significantly increased IPSP amplitudes to $132.7 \pm 4.4 \%$ of control (averaged over all stimulus strengths; $\mathrm{F}(2,30)=$ 43.67; $p<0.05 ; n=11$; Figure 4 a) and subsequent addition of ethanol in the presence of ghrelin further increased IPSP amplitudes to $153.9 \pm 5.6 \%$ of control $(p<0.05$ compared with ghrelin; $n=11)$. Again, ghrelin had no effect on 50 or $100 \mathrm{~ms}$ PPF ratio (control: $0.98 \pm 0.09(n=11)$ and $1.02 \pm$ $0.07(n=14)$; ghrelin: $1.06 \pm 0.09(n=11)$ and $1.05 \pm 0.07$ $(n=14)$; Figure $4 \mathrm{c})$, but superfusion of ethanol after ghrelin produced a significant decrease in 50 and $100 \mathrm{~ms}$ PPF ratio $(0.83 \pm 0.07 ; p<0.05 ; n=11$ and $0.83 \pm 0.07 ; p<0.05 ; n=14$, respectively; Figure 4c), suggesting enhanced presynaptic release of GABA. The additional increase in IPSP amplitude induced by $44 \mathrm{mM}$ ethanol was observable 6-8 min after ethanol application (Figure $4 \mathrm{e}$ ). To assess the effect of concomitant application of ghrelin and ethanol, we had to compare this with the effect of ethanol alone. Thus, we inverted the order of drug superfusion. Superfusion of ethanol significantly increased IPSP amplitude to $130.2 \pm$ $4.2 \%$ of control (averaged across all stimulus strengths; $\mathrm{F}(2,18)=4.213 ; p<0.05, n=7$; Figure $4 \mathrm{~b})$. Ethanol also decreased the 50 and $100 \mathrm{~ms}$ PPF ratio (control: $0.92 \pm 0.10$ $(n=7)$ and $1.14 \pm 0.11(n=7)$; ethanol: $0.74 \pm 0.04$ and $0.88 \pm 0.10(p<0.05)$, respectively; Figure $4 d)$. We observed the effects of ethanol within 5-6 min of superfusion (Figure 4f). The magnitude of the increase in IPSP amplitude induced by ethanol alone $(30 \%)$ was comparable to the magnitude of the additional increase in amplitude produced by applying ethanol after ghrelin (20\%) (Figure 4a and b). We further explored this aspect by applying ghrelin after the superfusion of ethanol alone. In the presence of ethanol, ghrelin did not further increase the mean IPSP amplitude, but actually diminished the effect of ethanol $(113.6 \pm 12.0 \%$ of control, $n=7$; Figure $4 \mathrm{~b}$ ). Superfusion of ghrelin following ethanol increased the 50 and $100 \mathrm{~ms}$ PPF ratio $(0.96 \pm 0.12$ and $1.07 \pm 0.09$, respectively; Figure $4 \mathrm{~d}$ ), but this effect did not reach statistical significance.

\section{Chronic Ethanol Exposure Does Not Alter Ghrelin Signaling in CeA Neurons}

To determine whether chronic ethanol exposure could alter the ghrelin signaling system in the CeA, we applied ghrelin and ethanol to neurons from CET rats. Overall ANOVA 
a

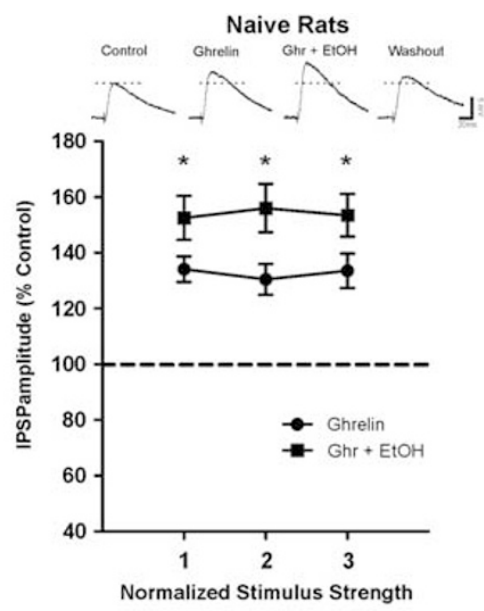

C

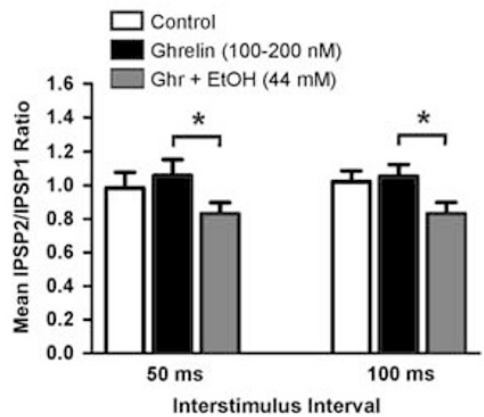

e

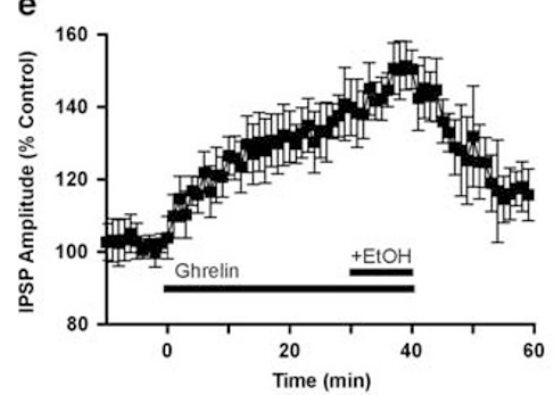

b
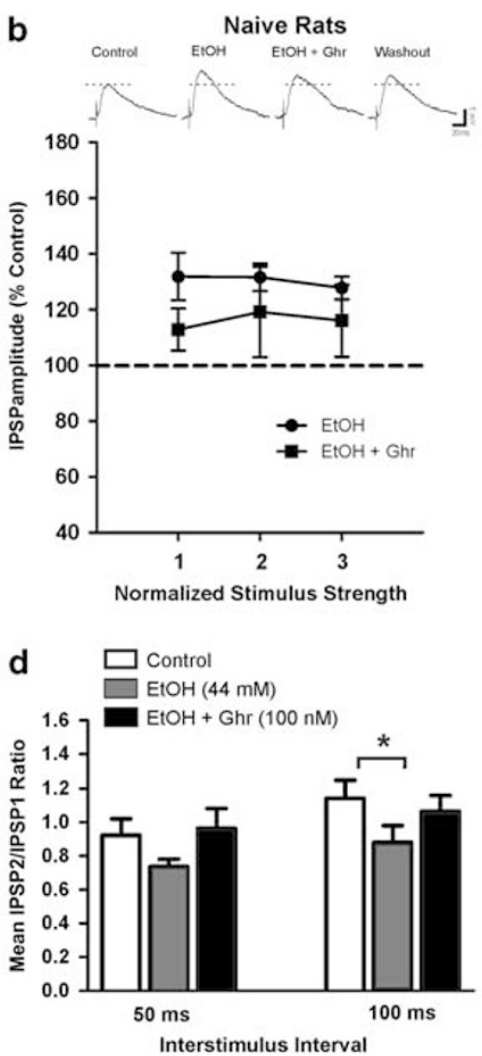

f

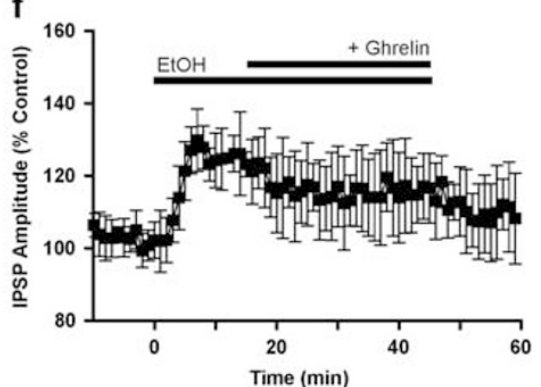

Figure 4 Ethanol further enhances evoked IPSP amplitude in CeA neurons. (a, top panel) Representative IPSP recordings in a CeA neuron during baseline, ghrelin (I00-200 nM), coapplication of ethanol (44 mM), and washout. (a, bottom panel) Ghrelin significantly $(* p<0.05, n=1 \mathrm{I})$ increases IPSP amplitudes to $132.7 \pm 4.4 \%$ of control. Coapplication of ethanol further increases IPSP amplitudes to $153.9 \pm 5.6 \%$ of control $(p<0.05, n=1 \mathrm{I})$. (b, top panel) Representative IPSP recordings in a CeA neuron during baseline, ethanol (44 mM), coapplication of ghrelin ( $100 \mathrm{nM})$, and washout. (b, bottom panel) Ethanol significantly increases IPSP amplitudes to $130.2 \pm 4.2 \%$ of control $(p<0.05, n=7)$. Coapplication of ghrelin reduces IPSP amplitudes to I | $3.6 \pm 12.0 \%$ of control ( $p>0.05$ compared with ethanol, $n=7$ ). (c) Ghrelin had no effect on 50 or 100 ms PPF ratio (control: $0.98 \pm 0.09$ ( $n=1$ I) and I.02 $\pm 0.07(n=14)$; ghrelin: $1.06 \pm 0.09(n=11)$ and I.05 $\pm 0.07(n=14))$. Coapplication of ethanol produced a decrease in 50 and $100 \mathrm{~ms}$ PPF ratio $(0.83 \pm 0.07 ; * 2<0.05 ; n=1 \mathrm{I}$ and $0.83 \pm 0.07 ; * p<0.05 ; n=14)$. (d) Ethanol decreased the 50 and $100 \mathrm{~ms}$ PPF ratio (control: $0.92 \pm 0.10$ ( $n=7$ ) and I.I4 \pm 0.1 I $(n=7)$; ethanol: $0.74 \pm 0.04$ and $0.88 \pm 0.10(* p<0.05)$ ). Ghrelin (I00 nM) does not change the 50 and $100 \mathrm{~ms}$ PPF ratio $(0.96 \pm 0.12$ and I.07 \pm 0.09). (e) Time course of changes in IPSP amplitude evoked by ghrelin (I00 nM), concurrent application of ethanol, and washout $(n=I I)$. ( $f$ ) Time course of changes in IPSP amplitude evoked by ethanol, concurrent application of ghrelin $(100 \mathrm{nM})$, and washout $(n=10)$.

showed a significant drug effect $(\mathrm{F}(2,18)=13.48 ; p<0.01)$. As in naive rats, superfusion of ghrelin $(100 \mathrm{nM})$ in CET CeA neurons increased IPSP amplitudes to $128.2 \pm 3.8 \%$ of control (averaged across all stimulus strengths; $p<0.05$; $n=7$; Figure $5 \mathrm{a}$ ), suggesting that ethanol dependence does not alter basal ghrelin signaling in the CeA. In contrast to naive rats, subsequent application of $44 \mathrm{mM}$ ethanol in CET rats did not further increase IPSP amplitude (it remained at $137.1 \pm 8.3 \%$ of control; $n=7$; Figure $5 \mathrm{a}$ ) or affect the 50 or $100 \mathrm{~ms}$ PPF ratio (control: $1.04 \pm 0.10(n=7)$ and $1.07 \pm 0.09$ $(n=10)$; ghrelin: $1.14 \pm 0.17$ and $1.18 \pm 0.13$; ghrelin with ethanol: $1.09 \pm 0.13$ and $1.04 \pm 0.11$, respectively; Figure $5 c$ ). Thus, in ethanol-dependent rats, the ghrelin-induced enhancement of GABA transmission completely preempted the effect of ethanol.

We performed a separate set of experiments in which we superfused $44 \mathrm{mM}$ ethanol onto slices from naive and ethanol-dependent rats. Consistent with our previous reports (Roberto et al, 2004, 2010), here we found that the increase in IPSP amplitude in the two groups of animals was similar (naive: $145.9 \pm 2.3 \%$ of control; $p<0.05, n=16$; CET: $137.8 \pm 7.1 \%$ of control; $p<0.05, n=10$; Figure $5 \mathrm{~b}$ ) and it 

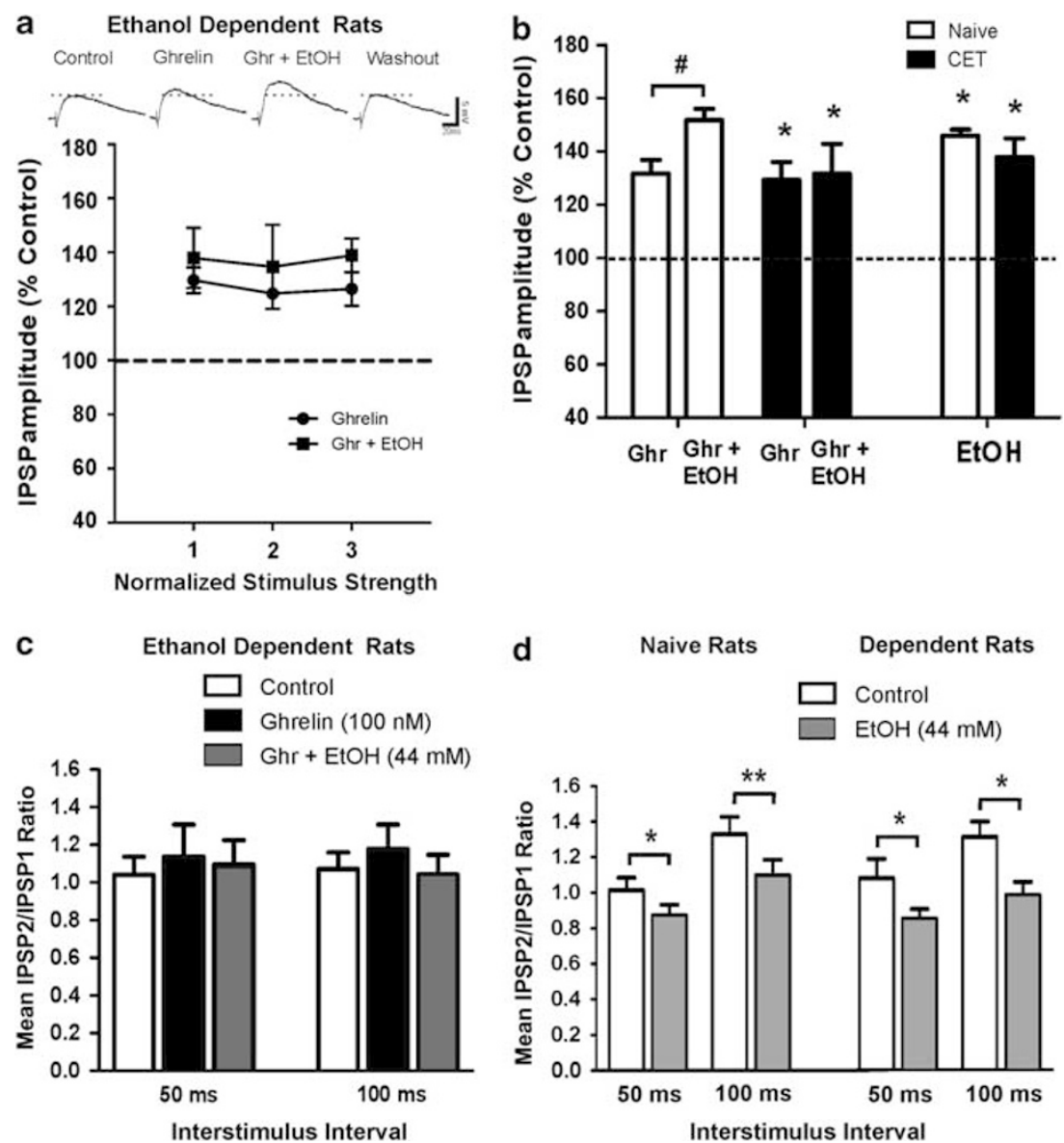

Figure 5 The effects of ghrelin on IPSPs are unchanged in CET rats. (a, top panel) Representative IPSP recordings in a CeA neuron from a CET rat during baseline, ghrelin (I00 nM), coapplication of ethanol (44 mM), and washout. (a, bottom panel) Ghrelin significantly $(p<0.05, n=7)$ increases IPSP amplitudes to $128.2 \pm 3.8 \%$ of control. After coapplication of ethanol, IPSP amplitudes remained at I37.I $\pm 8.3 \%$ of control ( $p>0.05$ compared with ghrelin, $n=7$ ). (b) Histograms depicting percent increase in evoked IPSP amplitudes (at half-max stimulus intensity) during ghrelin and coapplication of ethanol in naive and CET animals. In naive animals, ghrelin ( I 00-200 nM) increased IPSP amplitudes to I $31.6 \pm 5.1 \%$ of control (* $p<0.05, n=15)$ and the addition of ethanol (44 mM) increased IPSP amplitude to $151.7 \pm 4.4 \%$ of control ( $p_{p}<0.05$ compared with ghrelin, $\left.n=15\right)$. In CET animals, ghrelin increased IPSP amplitudes to $129.3 \pm 6.7 \%$ of control $(* p<0.05, n=9)$ and the addition of ghrelin $(I 00 \mathrm{nM})$ did not affect IPSP amplitude $(|3| .6 \pm|| 1.2 \%$ of control; $p>0.05, n=9)$. Ethanol increases IPSP amplitudes to $145.9 \pm 2.3 \%$ of control in naive animals $(* p<0.05, n=16)$ and $137.8 \pm 7.1 \%$ of control in CET animals ( $p<0.05$, $n=10$ ). $* 0.05$ compared with baseline control. (c) Ethanol does not affect the 50 or $100 \mathrm{~ms}$ PPF ratio in CET neurons pretreated with ghrelin (control: $1.04 \pm 0.10(n=7)$ and $1.07 \pm 0.09(n=10)$; ghrelin: $1.14 \pm 0.17$ and I.18 \pm 0.13 ; ghrelin with ethanol: $1.09 \pm 0.13$ and $1.04 \pm 0.11)$. (d) Ethanol (44 mM) decreases the 50 and $100 \mathrm{~ms}$ PPF ratio in both naive (control: $1.02 \pm 0.07(n=10)$ and $1.27 \pm 0.06(n=12)$; ethanol: $0.87 \pm 0.06(* p<0.05)$ and $1.03 \pm 0.08$ $(* * p<0.0 \mathrm{I})$ ) and CET rats (control: $1.08 \pm 0.1 \mathrm{I}(n=8)$ and I.3I $\pm 0.09(n=9)$; ethanol: $0.85 \pm 0.09(* p<0.05)$ and $0.99 \pm 0.09(* p<0.05)$ ).

was associated with a similar decrease in 50 and $100 \mathrm{~ms}$ PPF ratio in both naive (control: $1.02 \pm 0.07(n=10)$ and $1.27 \pm$ $0.06(n=12)$; ethanol: $0.87 \pm 0.06(p<0.05)$ and $1.03 \pm 0.08$ $(p<0.05)$, respectively) and CET rats (control: $1.08 \pm 0.11$ $(n=8)$ and $1.31 \pm 0.09(n=9)$; ethanol: $0.85 \pm 0.09(p<0.05)$ and $0.99 \pm 0.09(p<0.05)$, respectively; Figure $5 d)$.

\section{DISCUSSION}

Recent studies have implicated ghrelin and the GHS-R1A in alcohol consumption, and there is critical overlap in the neural pathways responsible for food consumption and those involved in excessive alcohol use (Thiele et al, 2003; Landgren et al, 2008; Landgren et al, 2010; Dickson et al, 2011; Leggio et al, 2011). Central ghrelin signaling mediates ethanol intake by activating GHS-R1As in the VTA, LDTg, and EWcp (Jerlhag et al, 2009; Kaur and Ryabinin, 2010).
However, the functional role of ghrelin in the CeA, an area critical for alcohol reward and reinforcement, has until now remained unknown. Here, we hypothesized that ghrelin signaling in the CeA modulates the effects of ethanol on GABAergic transmission, and may consequently play a role in alcohol reinforcement and excessive drinking. This is the first study to characterize the electrophysiological effects of ghrelin on GABAergic transmission and its interaction with ethanol in CeA. The results presented here reveal that ghrelin modulates GABAergic transmission in the rat CeA. Like ethanol (Roberto et al, 2003), ghrelin increases IPSP amplitudes in CeA neurons from both naive and ethanoldependent rats via pre- and post-synaptic mechanisms. When applied subsequent to ghrelin superfusion, ethanol further enhanced IPSP amplitudes in naive rats, but not in ethanol-dependent rats (Figure 5b). However, when applied first, ethanol occluded the ghrelin-induced increase in GABAergic transmission (Figure 4b). Finally, application 
of GHS-R1A antagonists revealed tonic facilitatory activity of the GHS-R1A on CeA GABAergic transmission. Analysis of mIPSCs confirms both pre- and post-synaptic sites of action. Taken together, these findings suggest an important role for the ghrelin system in regulating GABAergic transmission and shared mechanisms with ethanol in the CeA.

GHS-R1As have not been identified in the amygdala previously (Zigman et al, 2006), although Ghsr mRNA has been recently identified in the amygdalae of alcoholconsuming rats (Landgren et al, 2011b). Our qRT-PCR data revealing the presence of Ghsr mRNA in the CeA combined with our electrophysiological data indicate that functional GHS-R1As are present in the CeA and that these receptors are tonically active. Interestingly, the differences in expression levels are in agreement with the previous study showing higher levels of Ghsr mRNA in hippocampus than in VTA and amygdala, which are in turn higher than in nucleus accumbens and prefrontal cortex (Landgren et al, 2011b).

Blockade of GHS-R1A receptors with D-Lys3-GHRP-6 and JMV 3002 had a significant inhibitory effect on both evoked and spontaneous GABAergic activity, suggesting constitutive activation of GHS-R1As or tonic activity of endogenous ghrelin signaling in rat $\mathrm{CeA}$. Pretreatment of $\mathrm{CeA}$ neurons with the GHS-R1A antagonists completely blocked the ghrelin-induced facilitation of IPSP amplitudes (Figure 3d), indicating that ghrelin exerts its effect through GHS-R1As. However, GHS-R1A antagonism did not alter the ethanolinduced augmentation of IPSPs (Figure 3g), suggesting that these receptors do not mediate ethanol-induced IPSP enhancement and that ethanol effects in naive rats occur independently of GHS-R1A activation or blockade. In addition, in naive animals, ghrelin increased IPSP amplitude and ethanol produced a further increase, suggesting partially additive effects. Thus, the additive effect of ethanol may indicate that ghrelin and ethanol activate different intracellular mechanisms to increase GABAergic transmission. Ghrelin-induced increase in evoked IPSP amplitudes was not associated with a significant change in PPF ratio, but ethanol applied in the presence of ghrelin further increased the amplitude of evoked IPSPs and also significantly decreased PPF ratio, suggesting presynaptic effects of ethanol on GABA release. Interestingly, when ethanol is applied first, the facilitatory effects of ghrelin are completely abolished. The addition of ghrelin to the bath diminished the ethanol-induced enhancement of IPSP amplitude (Figure $4 \mathrm{~b}$ and $\mathrm{f}$ ), suggesting a preemptive effect of ethanol on ghrelin. This ethanol-induced facilitation of IPSPs was associated with a decrease in PPF (indicating increased GABA release) and blocked the ghrelin effects, suggesting that ethanol may have already activated ghrelin-dependent (shared) mechanisms.

These combined results indicate a complex cellular mechanism that underlies ethanol and ghrelin interactions in which the order of drug application plays an important role in these drug effects on GABAergic transmission in CeA. We speculate that ethanol activates intracellular mechanisms different from those activated by ghrelin only when ethanol is applied after ghrelin. These mechanisms may be presynaptic. Overall, ghrelin increases evoked GABA IPSP amplitudes without altering PPF ratios. However, ghrelin consistently increased the frequency and sometimes the amplitude of mIPSCs, suggesting an increase in both GABA release and $\mathrm{GABA}_{\mathrm{A}}$ receptor activation. In accord with the ghrelin data, GHS-R1A antagonists decrease evoked IPSPs without altering PPF ratios, and they also decrease both the frequencies and amplitudes of mIPSCs, pointing to both pre- and post-synaptic localization of GHSR1As, and also account for the pre- and post-synaptic effects of ghrelin. We interpret the absence of change in PPF ratios of evoked IPSPs by ghrelin and the GHS-R1A antagonists as the result of this combination of both preand post-synaptic effects, in which the postsynaptic effect may blunt or mask the presynaptic effect. However, we cannot rule out the fact that evoked and spontaneous GABAergic transmission may recruit different GABAergic synapses and also possibly different GABA vesicles. Perhaps, spontaneous GABAergic transmission is more sensitive than evoked transmission to the presynaptic action of ghrelin, and hence both ghrelin and its antagonists significantly alter the frequencies of mIPSCs but not the PPF ratio of evoked IPSPs. Ethanol increases GABAergic transmission via both preand post-synaptic mechanisms (Roberto et al, 2003), and when ethanol is applied after ghrelin pretreatment, it still increased evoked IPSP amplitude and decreased PPF ratio (Figure 4a and c), suggesting that the presynaptic effects of ethanol on GABA release are still active and may involve different GABA synapses or/and GABA vesicles.

The GHS-R1A is a G-protein-coupled receptor, and its activation results in cAMP signaling activity (Howard et al, 1996; Kojima et al, 1999). Our previous studies showed that the adenylate cyclase pathway is one of the second messenger pathways engaged by ethanol and CRF receptor activation (Cruz et al, 2011; Cruz et al, 2012). We speculate that the adenylate cyclase pathway may represent a common signaling pathway targeted in the same directions by ghrelin and ethanol in regulating GABAergic transmission, thus playing an essential role in their interactions. Ethanol- and ghrelin-dependent adenylate cyclase activation, in turn, could modulate downstream effector molecules such as voltage-sensitive $\mathrm{Ca}^{++}$channels and synaptotagmin, resulting in an increase in presynaptic GABA release. In CET rats, the ghrelin-induced increase in GABA was similar to that observed in naive animals, but ghrelin blocked the additional ethanol-induced increase typically seen in naive rats (Figure $5 b$ ). These results point to two critical considerations: (1) during the development of ethanol dependence, neuroadaptative changes occur in the GABAergic system, including those of presynaptic GABA function and presynaptic signaling engaged by ghrelin; (2) because an occlusive interaction occurred in CeA neurons from CET rats, we speculate that there are shared mechanisms between the two agents, likely at a presynaptic site. Ethanol increased GABA responses and reduced the PPF ratio in both naive (Figure $4 \mathrm{~b}$ and $\mathrm{d}$ ) and dependent rats (Figure $5 \mathrm{~b}$ and $\mathrm{d}$ ), which is consistent with enhanced GABA release elicited by ethanol (Roberto et al, 2003, 2004; Cruz et al, 2012). Our finding that ghrelin prevents both the ethanol-induced increase in GABA response (Figure 5b) and decrease in PPF ratio (Figure 5c) in CET animals suggests that those shared intracellular mechanisms may be presynaptic.

The fact that we observed no significant difference of ghrelin effect on evoked GABAergic transmission in CET animals (Figure 5b) suggests no neuroadaptation of 
GHS-R1As in CeA. This is in agreement with the involvement of ghrelin in food consumption, as mechanisms involved in food consumption should not adapt with prolonged experience with natural rewards. Based on our data, we cannot exclude the possibility that GHS-R1A levels did not change after ethanol dependence, and that CeA neurons adapt via other mechanisms, such as changes in signal transduction machinery. Further work is required to clarify possible synaptic mechanisms and signal transduction machinery affected by ethanol and ghrelin, and to determine if this tonic GHS-R1A activation is altered in CET animals or perhaps in different prandial states.

Activation of the ghrelin-GHS-R1A system during the development of alcohol dependence may have motivational significance. In mice, peripheral and central administration of ghrelin reduced the total number of entries and total time spent in the open arms in an elevated plus maze test (Asakawa et al, 2001a). Furthermore, starvation stress increased ghrelin gene expression (Asakawa et al, 2001b) and tail pinch stress significantly increased ghrelin mRNA expression (Asakawa et al, 2001a). These studies suggest that ghrelin induces potent anxiogenic activities, most likely via the CRF system. Ghrelin stimulates the HPA axis via stimulation of $\mathrm{CRH}$ release from the hypothalamus. Blockade of CRF receptors has been shown to attenuate ghrelin-induced anxiogenesis in the elevated plus maze test (Asakawa et al, 2001a), and injection of astressin (CRF2 receptor antagonist) attenuated ghrelin-induced plasma corticosterone increase in neonatal chicks (Saito et al, 2005). We have demonstrated that CRF, like ethanol, augments GABAergic transmission, and that ethanol dependence heightens the sensitivity to CRF and $\mathrm{CRF}_{1}$ antagonists in CeA (Roberto et al, 2010). Taken together with the data presented here, these studies suggest that central ghrelin signaling could possibly play a role in behavioral responses to alcohol withdrawal. The ghrelin system may constitute part of a brain pathway modulating reinforcement of alcohol consumption, and uncovering the role of ghrelin/ GHS-R1A and its interaction with ethanol in the CeA may provide a therapeutic target for the treatment of alcoholism.

\section{ACKNOWLEDGEMENTS}

This is manuscript number 20852 from The Scripps Research Institute. We thank Paul Schweitzer and Michal Bajo for their valuable comments. This work was supported by the Pearson Center for Alcoholism and Addiction Research and NIAAA Grants AA015566, AA06420, AA016985, AA017447, AA016647, AA013498, and AA010760.

\section{DISCLOSURE}

The authors declare no conflict of interest.

\section{REFERENCES}

Addolorato G, Capristo E, Leggio L, Ferrulli A, Abenavoli L, Malandrino N et al (2006). Relationship between ghrelin levels, alcohol craving, and nutritional status in current alcoholic patients. Alcohol Clin Exp Res 30: 1933-1937.
Andreasen M, Hablitz JJ (1994). Paired-pulse facilitation in the dentate gyrus: a patch-clamp study in rat hippocampus in vitro. J Neurophysiol 72: 326-336.

Asakawa A, Inui A, Kaga T, Yuzuriha H, Nagata T, Fujimiya M et al (2001a). A role of ghrelin in neuroendocrine and behavioral responses to stress in mice. Neuroendocrinology 74: 143-147.

Asakawa A, Inui A, Kaga T, Yuzuriha H, Nagata T, Ueno $\mathrm{N}$ et al (2001b). Ghrelin is an appetite-stimulatory signal from stomach with structural resemblance to motilin. Gastroenterology 120: 337-345.

Badaoui A, De Saeger C, Duchemin J, Gihousse D, de Timary P, Starkel P (2008). Alcohol dependence is associated with reduced plasma and fundic ghrelin levels. Eur J Clin Invest 38: 397-403.

Bajo M, Cruz MT, Siggins GR, Messing R, Roberto M (2008). Protein kinase $\mathrm{C}$ epsilon mediation of CRF- and ethanol-induced GABA release in central amygdala. Proc Natl Acad Sci USA 105: 8410-8415.

Benso A, Prodam F, Lucatello B, Gramaglia E, Riganti F, Schneider $\mathrm{H}$ et al (2007). d-Lys-GHRP-6 does not modify the endocrine response to acylated ghrelin or hexarelin in humans. Neuropeptides 41: 45-49.

Bonci A, Williams JT (1997). Increased probability of GABA release during withdrawal from morphine. J Neurosci 17: 796-803.

Cowley MA, Smith RG, Diano S, Tschop M, Pronchuk N, Grove KL et al (2003). The distribution and mechanism of action of ghrelin in the CNS demonstrates a novel hypothalamic circuit regulating energy homeostasis. Neuron 37: 649-661.

Cruz MT, Bajo M, Maragnoli ME, Tabakoff B, Siggins GR, Roberto $M$ (2011). Type 7 adenylyl cyclase is involved in the ethanol and CRF sensitivity of GABAergic synapses in mouse central amygdala. Front Neurosci 4: 207.

Cruz MT, Herman MA, Kallupi M, Roberto M (2012). Nociceptin/ orphanin FQ blockade of corticotropin-releasing factor-induced gamma-aminobutyric acid release in central amygdala is enhanced after chronic ethanol exposure. Biol Psychiatry 71: 666-676.

De Koninck Y, Mody I (1994). Noise analysis of miniature IPSCs in adult rat brain slices: properties and modulation of synaptic GABAA receptor channels. J Neurophysiol 71: 1318-1335.

Depoortere I, Thijs T, Peeters T (2006). The contractile effect of the ghrelin receptor antagonist, D-Lys3-GHRP-6, in rat fundic strips is mediated through 5-HT receptors. Eur J Pharmacol 537: 160-165.

Dickson SL, Egecioglu E, Landgren S, Skibicka KP, Engel JA, Jerlhag E (2011). The role of the central ghrelin system in reward from food and chemical drugs. Mol Cell Endocrinol 340: 80-87.

Funk CK, O'Dell LE, Crawford EF, Koob GF (2006). Corticotropinreleasing factor within the central nucleus of the amygdala mediates enhanced ethanol self-administration in withdrawn, ethanol-dependent rats. J Neurosci 26: 11324-11332.

Furness JB, Hunne B, Matsuda N, Yin L, Russo D, Kato I et al (2011). Investigation of the presence of ghrelin in the central nervous system of the rat and mouse. Neuroscience 193: 1-9.

Guan XM, Yu H, Palyha OC, McKee KK, Feighner SD, Sirinathsinghji DJ et al (1997). Distribution of mRNA encoding the growth hormone secretagogue receptor in brain and peripheral tissues. Brain Res Mol Brain Res 48: 23-29.

Howard AD, Feighner SD, Cully DF, Arena JP, Liberator PA, Rosenblum CI et al (1996). A receptor in pituitary and hypothalamus that functions in growth hormone release. Science 273: 974-977.

Hyytia P, Koob GF (1995). GABAA receptor antagonism in the extended amygdala decreases ethanol self-administration in rats. Eur J Pharmacol 283: 151-159.

Jerlhag E, Egecioglu E, Landgren S, Salome N, Heilig M, Moechars $\mathrm{D}$ et al (2009). Requirement of central ghrelin signaling for alcohol reward. Proc Natl Acad Sci USA 106: 11318-11323.

Kaur S, Ryabinin AE (2010). Ghrelin receptor antagonism decreases alcohol consumption and activation of perioculomotor 
urocortin-containing neurons. Alcohol Clin Exp Res 34: $1525-1534$.

Kim DJ, Yoon SJ, Choi B, Kim TS, Woo YS, Kim W et al (2005). Increased fasting plasma ghrelin levels during alcohol abstinence. Alcohol Alcohol 40: 76-79.

Kim J, Nakajima K, Oomura Y, Wayner MJ, Sasaki K (2009). Electrophysiological effects of ghrelin on pedunculopontine tegmental neurons in rats: an in vitro study. Peptides 30: 745-757.

Kojima M, Hosoda H, Date Y, Nakazato M, Matsuo H, Kangawa K (1999). Ghrelin is a growth-hormone-releasing acylated peptide from stomach. Nature 402: 656-660.

Koob GF (2003). Alcoholism: allostasis and beyond. Alcohol Clin Exp Res 27: 232-243.

Koob GF, Roberts AJ, Schulteis G, Parsons LH, Heyser CJ, Hyytia P et al (1998). Neurocircuitry targets in ethanol reward and dependence. Alcohol Clin Exp Res 22: 3-9.

Kraus T, Schanze A, Groschl M, Bayerlein K, Hillemacher T, Reulbach U et al (2005). Ghrelin levels are increased in alcoholism. Alcohol Clin Exp Res 29: 2154-2157.

Landgren S, Berglund K, Jerlhag E, Fahlke C, Balldin J, Berggren U et al (2011a). Reward-related genes and personality traits in alcohol-dependent individuals: a pilot case control study. Neuropsychobiology 64: 38-46.

Landgren S, Engel JA, Hyytia P, Zetterberg H, Blennow K, Jerlhag E (2011b). Expression of the gene encoding the ghrelin receptor in rats selected for differential alcohol preference. Behav Brain Res 221: 182-188.

Landgren S, Jerlhag E, Hallman J, Oreland L, Lissner L, Strandhagen E et al (2010). Genetic variation of the ghrelin signaling system in females with severe alcohol dependence. Alcohol Clin Exp Res 34: 1519-1524.

Landgren S, Jerlhag E, Zetterberg H, Gonzalez-Quintela A, Campos J, Olofsson U et al (2008). Association of pro-ghrelin and GHSR1A gene polymorphisms and haplotypes with heavy alcohol use and body mass. Alcohol Clin Exp Res 32: 2054-2061.

LeDoux JE, Iwata J, Cicchetti P, Reis DJ (1988). Different projections of the central amygdaloid nucleus mediate autonomic and behavioral correlates of conditioned fear. J Neurosci 8: 2517-2529.

Leggio L, Addolorato G, Cippitelli A, Jerlhag E, Kampov-Polevoy AB, Swift RM (2011). Role of feeding-related pathways in alcohol dependence: a focus on sweet preference, NPY, and ghrelin. Alcohol Clin Exp Res 35: 194-202.

Leggio L, Ferrulli A, Cardone S, Nesci A, Miceli A, Malandrino N et al (2012). Ghrelin system in alcohol-dependent subjects: role of plasma ghrelin levels in alcohol drinking and craving. Addict Biol 17: 452-464.

Manabe T, Wyllie DJ, Perkel DJ, Nicoll RA (1993). Modulation of synaptic transmission and long-term potentiation: effects on paired pulse facilitation and EPSC variance in the CA1 region of the hippocampus. J Neurophysiol 70: 1451-1459.

McBride WJ, Chernet E, McKinzie DL, Lumeng L, Li TK (1998). Quantitative autoradiography of mu-opioid receptors in the CNS of alcohol-naive alcohol-preferring $\mathrm{P}$ and -nonpreferring NP rats. Alcohol 16: 317-323.

Nie Z, Madamba SG, Siggins GR (1994). Ethanol inhibits glutamatergic neurotransmission in nucleus accumbens neurons by multiple mechanisms. J Pharmacol Exp Ther 271: 1566-1573.
Nie Z, Schweitzer P, Roberts AJ, Madamba SG, Moore SD, Siggins GR (2004). Ethanol augments GABAergic transmission in the central amygdala via CRF1 receptors. Science 303: 1512-1514.

Otis TS, De Koninck Y, Mody I (1994). Lasting potentiation of inhibition is associated with an increased number of gammaaminobutyric acid type A receptors activated during miniature inhibitory postsynaptic currents. Proc Natl Acad Sci USA 91: 7698-7702.

Roberto M, Cruz MT, Gilpin NW, Sabino V, Schweitzer P, Bajo M et al (2010). Corticotropin releasing factor-induced amygdala gamma-aminobutyric Acid release plays a key role in alcohol dependence. Biol Psychiatry 67: 831-839.

Roberto M, Madamba SG, Moore SD, Tallent MK, Siggins GR (2003). Ethanol increases GABAergic transmission at both preand postsynaptic sites in rat central amygdala neurons. Proc Natl Acad Sci USA 100: 2053-2058.

Roberto M, Madamba SG, Stouffer DG, Parsons LH, Siggins GR (2004). Increased GABA release in the central amygdala of ethanol-dependent rats. J Neurosci 24: 10159-10166.

Roberts AJ, Cole M, Koob GF (1996). Intra-amygdala muscimol decreases operant ethanol self-administration in dependent rats. Alcohol Clin Exp Res 20: 1289-1298.

Rogers J, Wiener SG, Bloom FE (1979). Long-term ethanol administration methods for rats: advantages of inhalation over intubation or liquid diets. Behav Neural Biol 27: 466-486.

Saito ES, Kaiya H, Tachibana T, Tomonaga S, Denbow DM, Kangawa $\mathrm{K}$ et al (2005). Inhibitory effect of ghrelin on food intake is mediated by the corticotropin-releasing factor system in neonatal chicks. Regul Pept 125: 201-208.

Salome N, Haage D, Perrissoud D, Moulin A, Demange L, Egecioglu E et al (2009). Anorexigenic and electrophysiological actions of novel ghrelin receptor (GHS-R1A) antagonists in rats. Eur J Pharmacol 612: 167-173.

Schiess MC, Callahan PM, Zheng H (1999). Characterization of the electrophysiological and morphological properties of rat central amygdala neurons in vitro. J Neurosci Res 58: 663-673.

Thiele TE, Navarro M, Sparta DR, Fee JR, Knapp DJ, Cubero I (2003). Alcoholism and obesity: overlapping neuropeptide pathways? Neuropeptides 37: 321-337.

Walker DL, Davis M (1997). Double dissociation between the involvement of the bed nucleus of the stria terminalis and the central nucleus of the amygdala in startle increases produced by conditioned versus unconditioned fear. J Neurosci 17: 9375-9383.

Wurst FM, Rasmussen DD, Hillemacher T, Kraus T, Ramskogler K, Lesch O et al (2007). Alcoholism, craving, and hormones: the role of leptin, ghrelin, prolactin, and the pro-opiomelanocortin system in modulating ethanol intake. Alcohol Clin Exp Res 31: 1963-1967.

Yanagida H, Morita T, Kim J, Yoshida K, Nakajima K, Oomura Y et al (2008). Effects of ghrelin on neuronal activity in the ventromedial nucleus of the hypothalamus in infantile rats: an in vitro study. Peptides 29: 912-918.

Zigman JM, Jones JE, Lee CE, Saper CB, Elmquist JK (2006). Expression of ghrelin receptor mRNA in the rat and the mouse brain. J Comp Neurol 494: 528-548.

Zucker RS (1989). Short-term synaptic plasticity. Annu Rev Neurosci 12: 13-31.

Supplementary Information accompanies the paper on the Neuropsychopharmacology website (http://www.nature.com/npp) 